\title{
Qualidade do fruto e produtividade do abacaxizeiro em diferentes densidades de plantio e lâminas de irrigação
}

\author{
Olegário Pinheiro de Souza(1), Reges Eduardo Franco Teodoro(2), Berildo de Melo(2) \\ e Jose Luiz Rodrigues Torres ${ }^{(1)}$
}

\begin{abstract}
(1)Instituto Federal de Educação, Ciência e Tecnologia Triângulo Mineiro, Avenida Edílson Lamartine Mendes, no 300, CEP 38045-000, Uberaba, MG. E-mail: opinheiro.@uol.com.br, jlrtorres@terra.com.br ${ }^{(2)}$ Universidade Federal de Uberlândia, Caixa Postal 593, CEP $38400-902$ Uberlândia, MG. E-mail: reges@ufu.br, berildo@ufu.br
\end{abstract}

\begin{abstract}
Resumo - O objetivo deste trabalho foi avaliar o efeito de diferentes densidades de plantio e duas lâminas de irrigação na qualidade do fruto e na produtividade do abacaxizeiro (Ananas comosus (L.) Merril). Utilizou-se o delineamento experimental de blocos ao acaso, com seis densidades de plantio e duas lâminas de irrigação, com cinco repetições. Avaliaram-se as características: peso médio, firmeza do fruto, diâmetro médio do fruto e do pedúnculo e o rendimento de suco dos frutos descascados. Foram quantificados as mudas tipo filhote, os rebentões e o rendimento total de frutos. O aumento na densidade de plantio causou a diminuição do peso, diâmetro médio dos frutos e do pedúnculo, rendimento de suco e número de mudas do tipo filhote. Contudo, não afetou a firmeza dos frutos. A maior lâmina de irrigação não influenciou o peso, nem o diâmetro médio dos frutos e do pedúnculo nem as mudas do tipo filhote, mas causou a diminuição na firmeza dos frutos e no rendimento de suco, nas populações de 35.714 e 71.429 plantas ha $^{-1}$. O rendimento total de frutos aumentou nas maiores densidades de plantio e não foi influenciado pelo aumento da lâmina de irrigação.
\end{abstract}

Termos para indexação: Ananas comosus, densidade de planta, evapotranspiração.

\section{Fruit quality and productivity of pineapple under different planting densities and irrigation levels}

\begin{abstract}
The objective of this work was to evaluate the effect of different planting densities and two irrigation levels on the fruit quality and productivity of pineapple (Ananas comosus (L.) Merril). A randomized block experimental design was used with six planting densities and two irrigation levels, with five replicates. Fruit weight, firmness, and juice yield were evaluated. The diameters of the fruit and of the stalk were also measured. The primary fruit, ratoon fruit, and the total fruit yield were calculated. The increase in planting density caused a decrease in the average fruit weight, diameter of the fruit and of the stalk, juice yield, and primary crop. However, plant density did not affect fruit firmness. The higher irrigation rate did not influence the fruit weight average, the diameter of the fruit and of the stem, or the primary crop, but did cause a decrease in fruit firmness and juice yield in the 35,714 and 71,429 plants ha ${ }^{-1}$ populations. The total fruit productivity increased with plant density and was not influenced by irrigation rate.
\end{abstract}

Index terms: Ananas comosus, plant density, evapotranspiration.

\section{Introdução}

O abacaxizeiro (Ananas comosus (L.) Merril) pertence à família Bromeliaceae e é originário da América do Sul, provavelmente das regiões Sul e Sudeste do Brasil, Argentina e Uruguai. Destacam-se como principais países produtores: Tailândia, Brasil, Filipinas, Estados Unidos (Havaí), China, Índia e Nigéria (Melo et al., 2006). Os três primeiros países detêm cerca de $40 \%$ da produção mundial (Ponciano et al., 2006).
Minas Gerais é um dos maiores produtores de abacaxi do país, com área atual de aproximadamente 7.600 ha cultivados, com produção de $597.895 \mathrm{Mg}$ (FNP Consultoria e Comércio, 2008). Estima-se que na região do Triângulo Mineiro haja uma área de plantio de abacaxi de 5.000 ha, com produção entre 30 e $35 \mathrm{Mg} \mathrm{ha}^{-1}$ de frutas (Granada et al., 2004).

Nas áreas de maior concentração de produção de abacaxi no Triângulo Mineiro, a estação chuvosa ocorre de outubro a março, e o período seco de abril a setembro.

Pesq. agropec. bras., Brasília, v.44, n.5, p.471-477, maio 2009 
Embora seja uma planta com necessidades hídricas relativamente baixas, quando comparada a outras espécies cultivadas, o abacaxizeiro apresenta demanda permanente porágua, variável e dependente de seu estágio de desenvolvimento (Almeida et al., 2002). Contudo, as fases críticas para a cultura concentram-se no período de crescimento vegetativo e floração, pois o deficit hídrico pode afetar a produção e, consequentemente, o peso do fruto e a qualidade (Carvalho et al., 2005).

Com a expansão da abacaxicultura irrigada no país, tanto em regiões tradicionalmente produtoras, quanto em novas áreas de plantio, aumentaram as demandas por tecnologias e informações que permitem manejo adequado da cultura. A maioria das áreas produtoras de abacaxi está sujeita a períodos secos, o que ocasiona deficit hídrico para a cultura. Nessas regiões, o uso da irrigação e densidades adequadas é importante para a elevação da produtividade e a melhoria da qualidade dos frutos (Souza, 2006).

O uso da irrigação no abacaxi possibilita plantios adensados, que é um dos fatores de produção mais importantes da cultura (Santana et al., 2001), e tem como consequência positiva o aumento da produtividade e da rentabilidade (Bengozi et al., 2007). Além disso, possibilita a produção de frutos padronizados e de melhor qualidade, o que resulta em maior retorno econômico. Possibilita ainda a colocação dos frutos no mercado no período de entressafra e a exploração de uma segunda safra, o que aumenta em até $30 \%$ a produtividade quando comparado ao cultivo em sequeiro (Souza et al., 2007).

Vários estudos têm relacionado o aumento da densidade de plantio e irrigação com alterações na qualidade do fruto e na produtividade do abacaxi em outras regiões produtoras do país (Cunha et al., 1999; Santana et al., 2001; Almeida et al., 2002; Thé et al., 2003; Melo et al., 2006; Bengozi et al., 2007). Contudo, ainda há carência de informações sobre o comportamento do abacaxizeiro irrigado e com alta densidade de planta, nas condições edafoclimáticas da região do Triângulo Mineiro. Este trabalho teve o objetivo de avaliar o efeito de diferentes densidades de plantio e de duas lâminas de irrigação, na qualidade do fruto e na produtividade do abacaxizeiro cultivar Smooth Cayenne, em Uberaba, MG.

\section{Material e Métodos}

O estudo foi conduzido de agosto de 2004 a dezembro de 2005, em área experimental no Município de Uberaba, MG, a 19³9'19"S e 47057'27"W e a 795 m de altitude. As médias anuais de temperatura máxima e mínima foram de 29 e $16,9^{\circ} \mathrm{C}$, respectivamente; a precipitação anual foi de 1.639,6 mm; a insolação anual foi de 360,4 horas e a umidade relativa do ar foi $64,9 \%$, em um período de dez anos, (Abdala, 2005) (Figura 1). No ano de 2005 , a precipitação anual $(1.482,79 \mathrm{~mm})$ esteve abaixo da média registrada na região nos últimos dez anos (1.639,6 mm). O clima da região é classificado como Aw, tropical quente, segundo Köppen, com inverno frio e seco (Prefeitura Municipal de Uberaba, 2007).

$\mathrm{O}$ solo da área experimental foi classificado como Latossolo Vermelho (Santos et al., 2006), com as seguintes características na camada arável (0-0,20 m): $200 \mathrm{~g} \mathrm{~kg}^{-1}$ de argila, $720 \mathrm{~g} \mathrm{~kg}^{-1}$ de areia e $80 \mathrm{~g} \mathrm{~kg}^{-1}$ de silte, $\mathrm{pH}-\mathrm{H}_{2} \mathrm{O}(1: 2,5) 6 ; 4,4 \mathrm{mg} \mathrm{dm}^{-3}$ de P (Mehlich); $114 \mathrm{mg} \mathrm{dm}^{-3}$ de K; 1,3 cmol $_{\mathrm{c}} \mathrm{dm}^{-3} \mathrm{de} \mathrm{Ca}^{2+}$; 0,6 $\mathrm{cmol}_{\mathrm{c}} \mathrm{dm}^{-3}$ de $\mathrm{Mg}^{2+} ; 1,7 \mathrm{cmol}_{\mathrm{c}} \mathrm{dm}^{-3}$ de $\mathrm{H}+\mathrm{Al}$ e $9 \mathrm{~g} \mathrm{dm}^{-3}$ de matéria orgânica.

O solo foi preparado de forma convencional, com uma aração e duas gradagens, e o plantio foi feito manualmente, e foram aplicados $3 \mathrm{~g}$ de $\mathrm{P}_{2} \mathrm{O}_{5}$ por cova. Foram efetuadas seis adubações de cobertura com $1 \mathrm{~g}$ de $\mathrm{N}$ (ureia) e 1,2 g de $\mathrm{K}_{2} \mathrm{O}$ (cloreto de potássio) por planta, aplicados nas axilas das folhas mais velhas. Além disso, realizaram-se três adubações foliares, com formulações com $12 \%$ de N, $20 \%$ de $\mathrm{K}, 10 \%$ de $\mathrm{Ca}, 4 \%$ de $\mathrm{Mg}, 5 \%$ de $\mathrm{Zn}, 6,5 \%$ de Fe, $8 \%$ de $\mathrm{S}$ e $2 \%$ de $\mathrm{B}$, aos 6,8 e 12 meses após o plantio. Foram aplicadas doses totais de $9 \mathrm{~g}$ de $\mathrm{N}, 3 \mathrm{~g}$ de $\mathrm{P}_{2} \mathrm{O}_{5}$ e $14 \mathrm{~g}$ de $\mathrm{K}_{2} \mathrm{O}$ por planta, conforme recomendações para a cultura no Estado de Minas Gerais (Ribeiro et al., 1999).

Foram utilizadas mudas da cultivar Smooth Cayenne do tipo rebentão, com aproximadamente $300 \mathrm{~g}$ e altura de 0,30 a $0,40 \mathrm{~m}$. As mudas foram submetidas à cura,

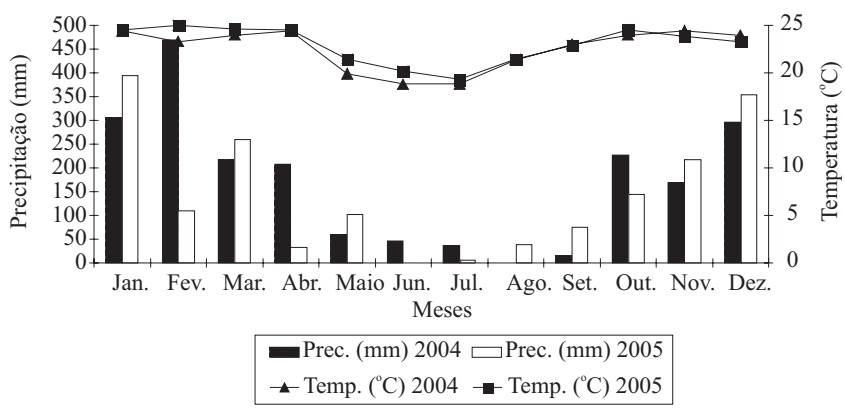

Figura 1. Temperatura e precipitação na Estação Meteorológica da Empresa de Pesquisa Agropecuária do Estado de Minas Gerais, nos anos agrícolas de 2004 e 2005, em Uberaba, MG. 
para eliminar o excesso de umidade, selecionadas e padronizadas de acordo com o peso, tamanho e sanidade. Todas passaram por tratamento em solução aquosa de fungicida à base de tiofanato metílico - grupo químico benzimidazol, nome comercial Cercobin 500 (100 g p.c. $100 \mathrm{~L}^{-1}$ de água) - e inseticida à base de paration metílico - grupo químico fosforado, nome comercial Folisuper 600 (100 mL $100 \mathrm{~L}^{-1}$ de água).

Utilizou-se o delineamento experimental de blocos ao acaso, com seis densidades de plantio (Tabela 1), duas lâminas de irrigação e com cinco repetições. As lâminas de irrigação foram calculadas para reposição diária de 100 e $120 \%$ da evapotranspiração da cultura (ETc) (Tabela 2). A parcela experimental, com 5x4,2 m, foi constituída de três linhas duplas, com as plantas dispostas em quincôncio na linha de plantio. Foram utilizadas 12 plantas centrais, de cada parcela, como plantas úteis, retiradas das linhas da fileira dupla do meio.

A irrigação foi realizada para repor diariamente a ETc, tendo-se considerado a ocorrência de precipitação na área entre irrigações consecutivas (Tabela 2). A ETc foi estimada a partir da evaporação diária da água do tanque Classe A (circundado por solo nu), corrigida pelo coeficiente do tanque (Kp), que foi obtido pela média dos valores propostos por Doorenbos \& Kassan (1979). O coeficiente Kp médio usado foi de 0,7, tendose determinado a vazão de $0,25 \mathrm{~L} \mathrm{~s}^{-1}$.

Para determinação de ETc, utilizou-se a equação: $\mathrm{ETc}=\mathrm{Kc} \times \mathrm{ETo}$, em que: ETc é a evapotranspiração da cultura $\left(\mathrm{mm} \mathrm{dia}^{-1}\right)$; Kc é o coeficiente da cultura (decimal); ETo é a evapotranspiração de referência $\left(\mathrm{mm} \mathrm{dia}{ }^{-1}\right)$. Para o cálculo da evapotranspiração de referência (ETo), utilizou-se a seguinte equação: $\mathrm{ETo}=\mathrm{Kp} \times \mathrm{ECA}$, em que: Kp é o coeficiente do tanque (decimal); ECA é a evaporação da água no tanque Classe A $\left(\mathrm{mm} \mathrm{dia}^{-1}\right)$. O coeficiente da cultura $(\mathrm{Kc})$ foi utilizado de acordo com o estádio de desenvolvimento, conforme proposto por Bernardo (1989), em que: estádio inicial, $\mathrm{Kc}=0,4$; estádio secundário, $\mathrm{Kc}=0,8$; estádio de produção, $\mathrm{Kc}=1$ e estádio de maturação, $\mathrm{Kc}=0,45$.

As lâminas de irrigação foram aplicadas com sistema de aspersão convencional: aspersores tipo

Tabela 1. Densidades de plantio e populações de plantas correspondentes, produção de frutos com coroa (FCC), e rendimento médio de suco (RMS) com lâminas de água para reposição de 100 e $120 \%$ da evapotranspiração da cultura (ETc), em Uberaba, $\mathrm{MG}^{(1)}$.

\begin{tabular}{|c|c|c|c|c|c|}
\hline Espaçamento $(\mathrm{cm})$ & População (plantas ha ${ }^{-1}$ ) & FCC $100 \%$ Etc $\left(\mathrm{Mg} \mathrm{ha}^{-1}\right)$ & FCC $120 \%$ Etc $\left(\mathrm{Mg} \mathrm{ha}^{-1}\right)$ & RMS $100 \%$ Etc $(\mathrm{kg})$ & RMS $120 \%$ Etc $(\mathrm{kg})$ \\
\hline $90 \times 50 \times 45$ & 31.746 & $43,7 \mathrm{aA}$ & $42,6 \mathrm{aA}$ & $0,8970 \mathrm{a}$ & $0,8911 \mathrm{a}$ \\
\hline $90 \times 50 \times 40$ & 35.714 & $46,3 \mathrm{aB}$ & $49,8 \mathrm{aB}$ & $0,8162 b$ & $0,9360 \mathrm{a}$ \\
\hline $90 \times 50 \times 35$ & 40.816 & $54,8 \mathrm{aC}$ & $54,4 \mathrm{aC}$ & $0,8475 a$ & $0,8568 \mathrm{a}$ \\
\hline $90 \times 50 \times 30$ & 47.619 & $62,4 \mathrm{aD}$ & $60,0 \mathrm{aD}$ & $0,8622 a$ & $0,8168 \mathrm{a}$ \\
\hline $90 \times 50 \times 25$ & 57.143 & $73,3 \mathrm{aE}$ & $69,9 \mathrm{aE}$ & $0,7882 \mathrm{a}$ & $0,7252 \mathrm{a}$ \\
\hline $90 \times 50 \times 20$ & 71.429 & $82,0 \mathrm{aF}$ & $74,2 \mathrm{aF}$ & $0,7529 \mathrm{a}$ & $0,5980 \mathrm{~b}$ \\
\hline
\end{tabular}

${ }^{(1)}$ Valores seguidos de letras iguais, minúsculas nas linhas e maiúsculas nas colunas, não diferem entre si pelo teste de Tukey, a 5\% de probabilidade.

Tabela 2. Índices utilizados para estimar lâminas de reposição da evapotranspiração da cultura (ETc).

\begin{tabular}{|c|c|c|c|c|c|}
\hline Meses & Evaporação no tanque Classe $\mathrm{A}$ & Precipitação & ETc & Reposição de $100 \%$ & Reposição de $120 \%$ \\
\hline $\mathrm{Ago}_{0} / 2004$ & 130.40 & 1.20 & $\frac{(\mathrm{mm})--}{41,08}$ & 40.03 & 48,03 \\
\hline Set./2004 & 196,84 & 6,00 & 62,00 & 61,54 & 73,84 \\
\hline Out./2004 & 197,44 & 151,24 & 62,19 & 45,30 & 54,36 \\
\hline Nov./2004 & 185,28 & 123,10 & 58,36 & 42,57 & 51,09 \\
\hline Dez./2004 & 155,28 & 323,30 & 48,91 & 23,02 & 27,62 \\
\hline Jan./2005 & 271,14 & 370,15 & 85,41 & 3,53 & 4,24 \\
\hline Fev./2005 & 172,20 & 121,82 & 54,24 & 34,74 & 41,69 \\
\hline Mar./2005 & 145,57 & 339,02 & 45,85 & 22,55 & 27,06 \\
\hline Abr./2005 & 148,70 & 48,25 & 83,27 & 67,57 & 81,08 \\
\hline Maio/2005 & 124,78 & 115,60 & 69,88 & 63,16 & 75,79 \\
\hline Jun./2005 & 104,55 & 28,85 & 56,42 & 49,35 & 59,22 \\
\hline Jul./2005 & 139,51 & 5,00 & 97,66 & 96,26 & 115,51 \\
\hline Ago./2005 & 183,20 & 10,20 & 128,24 & 126,40 & 151,68 \\
\hline Set./2005 & 160,92 & 73,30 & 112,64 & 75,72 & 90,86 \\
\hline Out./2005 & 212,84 & 51,60 & 148,99 & 131,31 & 157,57 \\
\hline Nov./2005 & 261,08 & 198,10 & 82,24 & 30,77 & 36,93 \\
\hline Dez./2005 & 114,16 & 120,90 & 35,96 & 2,13 & 2,56 \\
\hline Total & $2.903,89$ & $2.087,63$ & $1.273,36$ & 915,94 & $1.099,12$ \\
\hline
\end{tabular}


NAAN 5022, diâmetro dos bocais de 2,5x3,2 mm, espaçados de $12 \times 12 \mathrm{~m}$, com pressão na saída da bomba

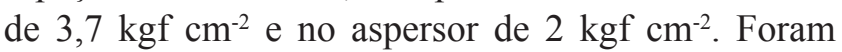
instalados coletores, entre os dois aspersores centrais, em uma malha composta de 84 coletores, dispostos de $2 \times 2 \mathrm{~m}$, o que garantiu que, no mínimo, 50 coletores sob os aspersores recebessem água. A borda do copo coletor ficou à altura de $0,30 \mathrm{~m}$ do nível do solo.

Foram avaliadas as características: peso médio do fruto com e sem coroa, em balança semianalítica com precisão de $0,001 \mathrm{~g}$; diâmetro médio do fruto e do pedúnculo, medido com paquímetro; firmeza do fruto, com o penetrômetro para frutas FT 327; rendimento de suco, usando frutos descascados com faca inoxidável e colocados em uma despolpadeira marca Itametal, modelo 025DF; número de filhotes e rebentões; rendimento total e produtividade de frutos com e sem coroa, conforme normas analíticas propostas pelo Instituto Adolfo Lutz (1985).

As avaliações foram submetidas à análise de variância. As médias foram comparadas pelo teste de Tukey, a $5 \%$ de probabilidade. Para os efeitos qualitativos, aplicou-se o teste $\mathrm{t}$ de Student, e para os efeitos quantitativos, os dados foram ajustados a um modelo de regressão conforme Banzatto \& Kronka (1989). A análise estatística foi realizada com o SISVAR (Ferreira, 2000).

\section{Resultados e Discussão}

Neste trabalho, ocorreu correlação significativa e negativa entre densidade de plantas e o peso médio do fruto com e sem coroa (PMCC e PMSC) (Figura 2). $\mathrm{O}$ mesmo fato ocorreu com o diâmetro médio do fruto (DMF) e do pedúnculo (DMP) (Figura 3). Essa constatação está diretamente relacionada à competição por água, luminosidade e nutrientes, pois o adensamento altera a uniformidade de crescimento das plantas, conforme destacado por Cunha (1999). Segundo Santana et al. (2001) e Granada et al. (2004), a produtividade da cultivar Smooth Cayenne aumenta nas maiores densidades de plantio, ocorre entretanto a diminuição no peso médio dos frutos. Cunha (1999) e Melo et al. (2004) destacam que para densidades de até 50 mil plantas por hectare, esta característica não sofre alteração.

Entretanto, mesmo com a diminuição do PMCC e PMSC, o peso médio obtido no presente trabalho foi de $1,5 \mathrm{~kg}$ por fruto (Tabela 3), que está no limite de preferência dos mercados consumidores brasileiros, que é de frutos com peso acima de $1,5 \mathrm{~kg}$ e bem acima para o mercado internacional, que exige frutos com peso entre 0,5 e $1 \mathrm{~kg}$ (Santana et al., 2001). Bengozi et al. (2007) destacam que, no mercado brasileiro, existe grande variação quanto ao peso médio dos frutos comercializados, em razão do nível de tecnologia empregado em cada região.

Não houve diferença significativa entre as lâminas de água de irrigação quanto ao peso e o diâmetro médio dos frutos e do pedúnculo (Tabela 3), diferentemente dos resultados observados por Souza et al. (2007), com a cultivar Pérola.

A firmeza dos frutos com e sem casca (FFCC e FFSC) não foi influenciada pela densidade de plantas $(\mathrm{p}>0,05)$, entretanto o aumento da lâmina de água de 100 para $120 \%$ da ETc influenciou significativamente esta variável qualitativa $(p<0,05)$, de forma negativa (Tabela 3 ), pois

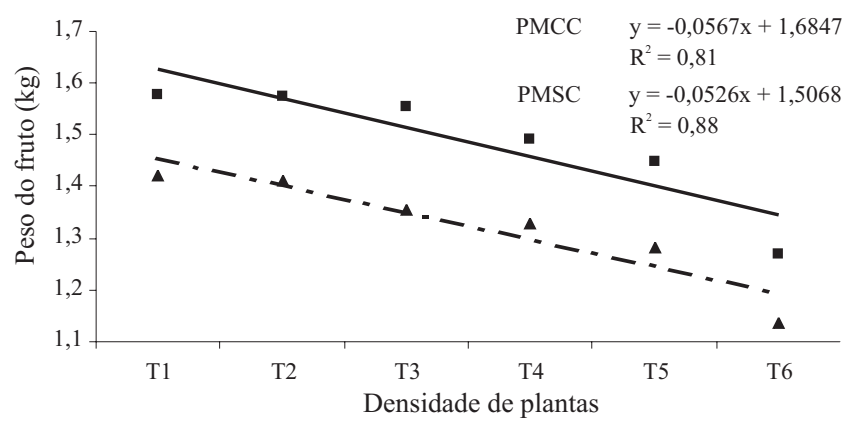

Figura 2. Peso médio de frutos de abacaxi com (PMCC, $\boldsymbol{~}$ ) e sem coroa (PMSC, $\mathbf{A}$ ), em Uberaba, MG, em resposta a diferentes densidades de plantio (T1 a T6: 31.746, $35.714,40.816,47.619,57.143$ e 71.429 plantas por hectare, respectivamente).

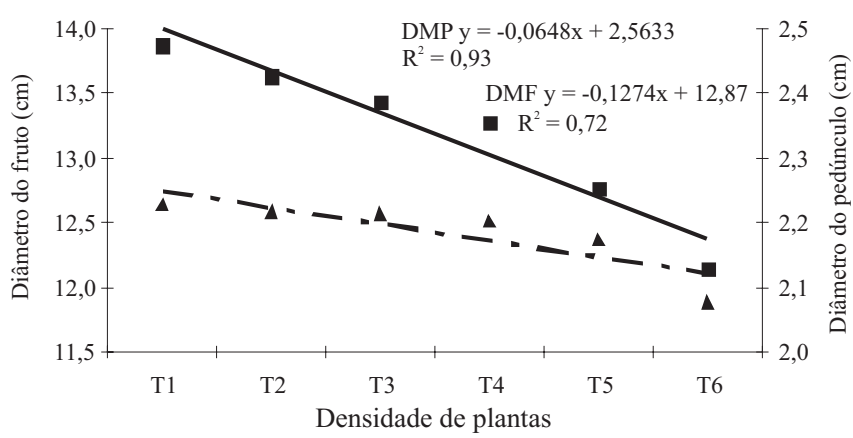

Figura 3. Diâmetro médio do fruto (DMF, $\square$ ) e do pedúnculo (DMP, $\mathbf{\Delta}$ ) de abacaxi, em Uberaba, MG, em resposta a diferentes densidades de plantio (T1 a T6: 31.746, 35.714, 40.816, 47.619, 57.143 e 71.429 plantas por hectare, respectivamente). 
os frutos ficaram menos firmes e mais susceptíveis a danos mecânicos, por ocasião do transporte a granel, que causam prejuízos para sua comercialização e industrialização (Pinheiro et al., 2005).

Para a indústria de alimentos, o suco é o produto nobre do abacaxi, tanto para consumo in natura, quanto para fabricação de vários subprodutos e para exportação (Granada et al., 2004). Por isso, o suco é um dos parâmetros mais importantes de avaliação. $\mathrm{O}$ aumento da densidade de plantio causou decréscimo nos valores de rendimento de suco (RS) de até $24 \%$ (Figura 4). Esses valores estão correlacionados ao peso e diâmetro médio dos frutos, que também diminuíram, influenciados pela competição que ocorre entre plantas quando adensadas, conforme destacado por Melo et al. (2006). O aumento da lâmina de água de irrigação de 100 para $120 \%$ da ETc aumentou significativamente o rendimento médio do suco dos frutos na população de 35.714 plantas ha-1 $^{-1}$ (Tabela 1). Na maior população de plantas (71.429 plantas ha-1), a produção de frutos foi menor na lâmina de reposição da ETc de 120\%. Esta situação ocorreu, provavelmente, em razão da menor firmeza da casca dos frutos, lixiviação de nutrientes pelo maior volume de água aplicada e competição por luminosidade (Souza, 2006).

O número de mudas do tipo filhote (MTF) diminuiu à medida que se aumentou a densidade de plantas (Figura 5). Contrariamente, Santana et al. (2001) observaram que o número de mudas aumentou em densidades maiores, porém o vigor dessas mudas obtidas era inferior em comparação às obtidas em densidades menores. Observou-se que ocorreu, também, a diminuição do número de mudas tipo filhote quando se aumentou a lâmina de reposição da ETc. Não ocorreu diferença significativa para mudas do tipo rebentão, entre as densidades de plantio e as lâminas de reposição avaliadas (Tabela 3 ).

Os valores obtidos para as variáveis de produção indicam que as maiores densidades de plantio proporcionaram aumento no rendimento total de frutos com (RTCC) e sem coroa (RTSC) (Figura 6). Entretanto, o mesmo fato não ocorreu com as lâminas de reposições da ETc, que não diferiram significativamente entre si para essas variáveis (Tabela 1). Pode-se destacar que, no presente trabalho, os efeitos da irrigação e da densidade de plantas ocorreram de forma isolada para

Tabela 3. Análise de variância dos dados de número de mudas tipo filhote (MTF) e tipo rebentão (MTR), rendimento total do fruto com (RTCC) e sem casca (RTSC), peso médio de fruto com (PMCC) e sem coroa (PMSC), diâmetro médio do fruto (DMF) e do pedúnculo (DMP), firmeza do fruto com (FFCC) e sem casca (FFSC), em Uberaba, MG.

\begin{tabular}{|c|c|c|c|c|c|c|c|c|c|c|c|}
\hline \multirow[t]{3}{*}{ Fonte de variação } & \multirow[t]{3}{*}{ GL } & \multicolumn{10}{|c|}{ Quadrado médio } \\
\hline & & MTF & MTR & RTCC & RTSC & PMCC & PMSC & DMF & DMP & FFCC & FFSC \\
\hline & & \multicolumn{2}{|c|}{------(unidade)------ } & \multicolumn{2}{|c|}{-----(Mg ha'-1)------ } & \multicolumn{2}{|c|}{ 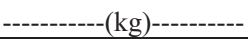 } & \multicolumn{2}{|c|}{ 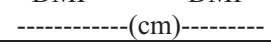 } & \multicolumn{2}{|c|}{------ $\left(\mathrm{kgf} \mathrm{cm}^{-2}\right)$------- } \\
\hline$\overline{\text { Densidade (D) }}$ & 5 & $0,843^{*}$ & $0,035^{\mathrm{ns}}$ & $2.430,610^{*}$ & $172,350 *$ & $0,138^{*}$ & $0,143 *$ & $0,787^{*}$ & $0,159 *$ & $0,937^{\mathrm{ns}}$ & $0,615^{\mathrm{ns}}$ \\
\hline Lâmina (L) & 1 & $1,148^{*}$ & $0,081^{\mathrm{ns}}$ & $76,281^{\mathrm{ns}}$ & $92,993^{\text {ns }}$ & $0,014^{\mathrm{ns}}$ & $0,017^{\mathrm{ns}}$ & $0,001^{\mathrm{ns}}$ & $0,085^{*}$ & $5,239 *$ & $2,007 *$ \\
\hline DxL & 5 & $0,043^{\text {ns }}$ & $0,057^{\mathrm{ns}}$ & $53,196^{\mathrm{ns}}$ & $66,616^{\text {ns }}$ & $0,020^{\mathrm{ns}}$ & $0,020^{\mathrm{ns}}$ & $0,115^{\mathrm{ns}}$ & $0,008^{\mathrm{ns}}$ & $0,970^{\mathrm{ns}}$ & $0,332^{\mathrm{ns}}$ \\
\hline Erro & 40 & 0,196 & 0,061 & 27,062 & 34,667 & 0,009 & 0,011 & 0,073 & 0,013 & 1,153 & 0,368 \\
\hline$\overline{\mathrm{CV}}(\%)$ & & 34,00 & 20,85 & 7,53 & 9,60 & 6,60 & 0,01 & 2,18 & 4,87 & 20,12 & 19,16 \\
\hline Média & & 1,34 & 1,18 & 69,06 & 61,34 & 1,50 & 1,43 & 12,4 & 2,34 & 5,34 & 3,17 \\
\hline
\end{tabular}

${ }^{n}$ Não significativo. *Significativo a $5 \%$ de probabilidade, pelo teste de Tukey.

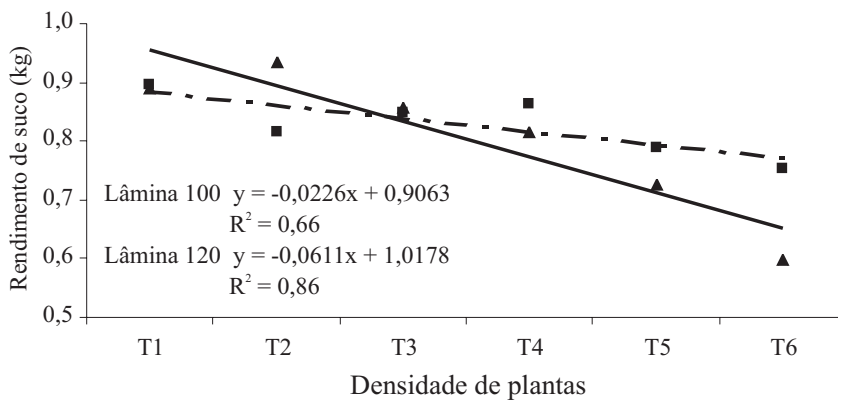

Figura 4. Rendimento médio de suco (RS) do abacaxi, com as lâminas de reposição de $100(\boldsymbol{\nabla})$ e $120 \%$ (A) da evapotranspiração da cultura, em Uberaba, $\mathrm{MG}$, em resposta a diferentes densidades de plantio (T1 a T6: 31.746, 35.714, 40.816, 47.619, 57.143 e 71.429 plantas por hectare, respectivamente).

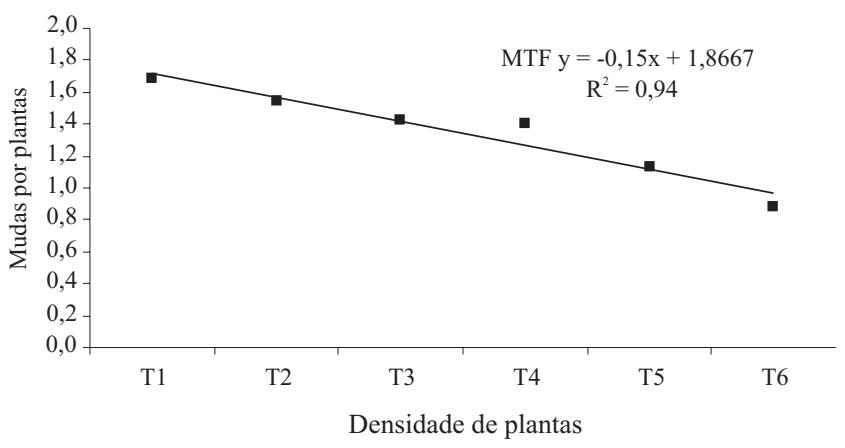

Figura 5. Número de mudas tipo filhote (MTF) de abacaxi, em Uberaba, MG, em resposta a diferentes densidades de plantio (T1 a T6: 31.746, 35.714, 40.816, 47.619, 57.143 e 71.429 plantas por hectare, respectivamente). 
os fatores RTCC e RTSC, não tendo ocorrido interação significativa entre eles (Tabela 3). Esses resultados foram semelhantes aos observados por Melo et al. (2004, 2006), em outra região.

A produtividade de frutos é um fator importante a ser destacado, pois a cultivar Smooth Cayenne apresenta potencial para o uso de altas densidades de plantio, e pode atingir produtividade elevada, a depender das condições climáticas de cada região. No presente trabalho foram observadas diferenças significativas entre as densidades de plantas, quanto à produção de frutos com coroa (FCC), entretanto, o mesmo fato não ocorreu quando se compararam as duas lâminas de irrigação aplicadas (Tabela 1). Os valores de produtividade variaram de 43,7 a $82 \mathrm{Mg} \mathrm{ha}^{-1}$, com reposição de $100 \%$ da ETc, e de 42,6 a $74,2 \mathrm{Mg} \mathrm{ha}^{-1}$ com reposição de $120 \%$ da ETc (Tabela 1). Essas produtividades são superiores às registradas no Triângulo Mineiro, em condições de sequeiro, que foram de 30 a $35 \mathrm{Mg} \mathrm{ha}^{-1}$ (Granada et al., 2004). Estudos realizados em outras regiões mostram que os valores de produtividade são muito variáveis, tanto em condições de sequeiro (Santana et al., 2001), quanto em condições irrigadas (Almeida et al., 2002).

Os valores de produtividade elevados, obtidos no presente trabalho, estão diretamente relacionados à irrigação realizada de abril a setembro, que é o período seco da região (Figura 1), quando são aplicados os maiores volumes de água nos sistemas de irrigação. Mesmo não tendo ocorrido diferenças significativas com relação às lâminas aplicadas, as plantas não passaram por períodos de deficit hídrico. Como consequência disto, se obtiveram valores elevados de produtividade.

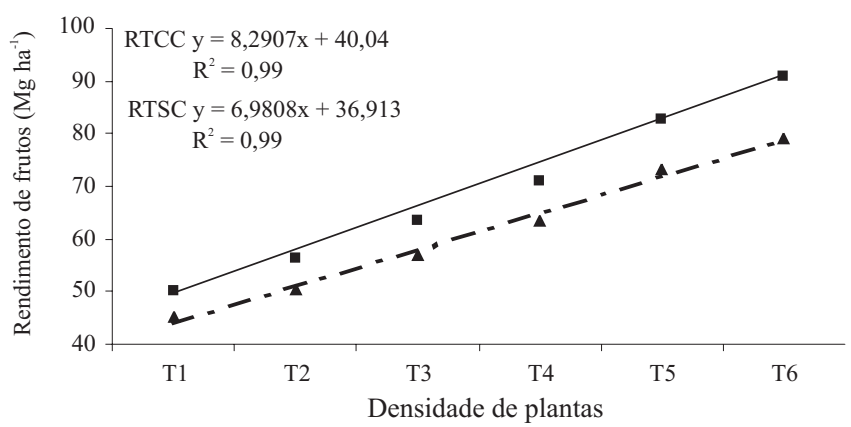

Figura 6. Rendimento total de frutos de abacaxi com (RTCC, $\boldsymbol{~}$ ) e sem coroa (RTSC, $\mathbf{A}$ ), em Uberaba, MG, em resposta a diferentes densidades de plantio (T1 a T6: 31.746, $35.714,40.816,47.619,57.143$ e 71.429 plantas por hectare, respectivamente).

\section{Conclusões}

1. O aumento na densidade de plantio causa a diminuição do peso médio dos frutos, diâmetro médio dos frutos e do pedúnculo, rendimento de suco e número de mudas do tipo filhote.

2. O aumento na lâmina de irrigação de 100 para $120 \%$ da evapotranspiração da cultura (ETc) causa diminuição na firmeza dos frutos e no rendimento de suco.

3. O rendimento total e a produtividade de frutos são maiores nas maiores densidades de plantas e não aumentam com o aumento na lâmina de irrigação de 100 para $120 \%$ da ETc.

\section{Referências}

ABDALA, V.L. Zoneamento ambiental da bacia do alto curso do rio Uberaba, MG, como subsídio para gestão do recurso hídrico superficial. 2005. 73p. Dissertação (Mestrado) - Universidade Federal de Uberlândia, Uberlândia.

ALMEIDA, O.A. de; SOUZA, L.F. da S.; REINHARDT, D.H.; CALDAS, R.C. Influência da irrigação no ciclo do abacaxizeiro cv. Pérola em área do tabuleiro costeiro da Bahia. Revista Brasileira de Fruticultura, v.24, p.431-435, 2002.

BANZATTO, D.A.; KRONKA, S. do N. Experimentação agrícola. Jaboticabal: Funep, 1989. 247p.

BENGOZI, F.J.; SAMPAIO, A.C.; GUTIERREZ, A.D. de S.; RODRIGUES, V.M.; PALLAMIN, M.L. Qualidades físicas e químicas do abacaxi comercializado na Ceagesp - São Paulo. Revista Brasileira de Fruticultura, v.29, p.540-545, 2007.

BERNARDO, S. Manual de irrigação. 5.ed. Viçosa: UFV, 1989. $596 \mathrm{p}$.

CARVALHO, S.L.C. de; NEVES, C.S.V.J.; BÜRKLE, R.; MARUR, C.J. Épocas de indução floral e soma térmica do período do florescimento à colheita de abacaxi 'Smooth Cayenne'. Revista Brasileira de Fruticultura, v.27, p.430-433, 2005.

CUNHA, G.A.P. da. Implantação da cultura. In: CUNHA, G.A.P. da; CABRAL, J.R.S.; SOUZA, L.F. da. S. (Org.). O abacaxizeiro: cultivo, agroindústria e economia. Brasília: Embrapa Comunicação para Transferência de Tecnologia, 1999. p.139-167.

DOORENBOS, J.; KASSAM, A.H. Yield response to water. Rome: Food and Agriculture Organization of the United Nations, 1979. 306p. (FAO. Irrigation and Drainage Paper, 33).

FERREIRA, D.F. SISVAR: sistema de análises de variância de dados balanceados: programa de análises estatísticas e planejamento de experimentos. Versão 4.3. Lavras: Ufla, 2000.

FNP CONSULTORIA E COMÉRCIO. Agrianual: anuário para a agricultura brasileira. São Paulo: FNP Consultoria e Comércio, 2008. p.148-156.

GRANADA, G.G.; ZAMBIAZI, R.C.; MENDONÇA, C.R.B. Abacaxi: produção, mercado e subprodutos. Boletim do CEPPA, v.22, p.405-422, 2004 
INSTITUTO ADOLFO LUTZ. Normas analíticas, métodos químicos e físicos para análise de alimentos. 3.ed. São Paulo: Instituto Adolfo Lutz, 1985. v.1.533p.

MELO, A.S. de; AGUIAR NETTO, A. de O.; DANTAS NETO, J.; BRITO, M.E.B.; VIÉGAS, P.R.A.; MAGALHÃES, L.T.S.; FERNANDES, P.D. Desenvolvimento vegetativo, rendimento da fruta e otimização do abacaxizeiro cv. Pérola em diferentes níveis de irrigação. Ciência Rural, v.36, p.93-98, 2006.

MELO, A.S. de; MÉLO, D.L.F.M. de; COSTA, L.A.; GÓES, M.P.P.; VIÉGAS, P.R.A. Rendimento, qualidade da fruta e lucratividade do abacaxizeiro cv. Pérola em diferentes espaçamentos. Revista de Ciências Agrárias, n.41, p.185-192, 2004.

PINHEIRO, A.C.M.; BARROS, E.V.B. de; LIMA, L.C. Influência do $\mathrm{CaCl}_{2}$ sobre a qualidade pós-colheita do abacaxi cv. Pérola. Ciência e tecnologia de alimentos, v.25, p.32-36, 2005.

PONCIANO, N.J.; CONSTANTINO, C.O.R.; SOUZA, P.M. de; DETMANN, E. Avaliação econômica da produção de abacaxi (Ananas comosus L.) cultivar Pérola na região Norte Fluminense. Revista Caatinga, v.19, p.82-91, 2006.

PREFEITURA MUNICIPAL DE UBERABA. Uberaba em dados. 2007. Disponível em: <www.uberaba.mg.gov.br/sedet/uberaba_ em_dados_2007>. Acesso em: 21 jan. 2009.

RIBEIRO, A.C.; GUIMARÃES, P.T.G.; ALVAREZ VENEGAS, V.H. Recomendações para o uso de corretivos e fertilizantes em
Minas Gerais. 5a aproximação. Viçosa: Comissão de Fertilidade do Solo do Estado de Minas Gerais, 1999. 359p.

SANTANA, L.L. de A.; REINHARDT, D.H.; CUNHA, G.A.P. da; CALDAS, R.C. Altas densidades de plantio na cultura do abacaxi cv. Smooth Cayenne, sob condições de sequeiro. Revista Brasileira de Fruticultura, v.23, p.353-358, 2001.

SANTOS, H.G. dos; JACOMINE, P.K.T.; ANJOS, L.H.C. dos; OLIVEIRA, V.A. de; OLIVEIRA, J.B. de; COELHO, M.R.; LUMBRERAS, J.F.; CUNHA, T.J.F. (Ed.). Sistema brasileiro de classificação de solos. 2.ed. Rio de Janeiro: Embrapa-Solos, 2006. $306 \mathrm{p}$.

SOUZA, C.B. de; SILVA, B.B. da;AZEVEDO, P.V. de. Crescimento e rendimento do abacaxizeiro nas condições climáticas dos Tabuleiros Costeiros do Estado da Paraíba. Revista Brasileira de Engenharia Agrícola e Ambiental, v.11, p.134-141, 2007.

SOUZA, O.P. Densidades de plantio e irrigação nas características físicas e químicas do abacaxi cultivar Smooth Cayenne. 2006. 70p. Dissertação (Mestrado) - Universidade Federal de Uberlândia, Uberlândia.

THÉ, P.M.P; GONÇALVES, N.B.; NUNES, R. de P.; MORAIS, A.R. de; PINTO, N.A.V.D.; FERNANDES, S.M.; CARVALHO, V.D. Efeitos de tratamentos pós-colheita sobre fatores relacionados à qualidade de abacaxi cv. Smooth Cayenne. Revista Brasileira de Agrociência, v.9, p.163-170, 2003.

Recebido em 4 de fevereiro de 2009 e aprovado em 30 de abril de 2009 